\title{
Dampak Sosial Ekonomi Pariwisata Terhadap Pedagang Souvenir Di Daya Tarik Wisata Pura Gunung Kawi Tampaksiring Gianyar
}

Ni Wayan Ariyoshi Sastra Ningsiha, 1, Ida Ayu Suryasiha, 2

1yoshiariyoshi@gmail.com, 2idaayusuryasih@unud.ac.id

a Program Studi S1 Destinasi Pariwisata, Fakultas Pariwisata,Universitas Udayana, Jl. Dr. R. Goris, Denpasar, Bali 80232 Indonesia

\begin{abstract}
The tourism grows fastly and attract more villagers and local organization to develop tourism industry in order to get an income for their own region. It should give benefits for local people, government and investors. Tourism is an activity that involves the local community, and also bring impacts to them. One of the of tourism sector is socio-economic. Socio-economic impact of tourism is generally focus on the change of sales, incomes, and employments.

This research has been conduct in Gunung Kawi Temple, Tampaksiring, Gianyar. This research aims to determine the socio-conomic impacts of tourism toward souvenir sellers who are part of local people. The data are collected through observation, interviews, questionnaires, and literature study.

The results of this study show that tourism activities in Gunung Kawi Temple give positive impacts toward the job opportunity and a good response from the souvenir sellers. However, the tourism development also brings negative impacts toward the price of products, and it becomes cheaper. This happen because they compete to sell the similiar products. In addition, they have an unfriendly attitude to offer their products to the tourists.

The managers of this tourist attraction (in this case are local people and government) should improve the design of souvenir kiosks to make it more clean and beautiful to tourists. They should give more trainingto the seller about good attitude of selling products. They also should give motivations to handicraft makers to make them keep innovate and invent new products, therefore the product will be more varieted.
\end{abstract}

Keywords: Socio-Economic Impact of Tourism, Souvenir Sellers, Gunung Kawi Temple

\section{PENDAHULUAN}

Pariwisata memegang peranan penting dalam pembvangunan ekonomi di berbagai negara. Sektor pariwisata merupakan sektor yang potensial untuk dikembangkan sebagai salah satu sumber pendapatan daerah. Program pengembangan dan pendayagunaan sumber daya dan potensi pariwisata daerah diharapkan dapat memberikan sumbangan bagi pembangunan ekonomi dalam usaha memperoleh pendapatan asli daerah.

Pariwisata mempunyai berbagai dampak ekonomi. Menurut Wahab (2007) menyatakan bahwa dampak kegiatan pariwisata dari segi ekonomi tidak saja lebih berpengaruh dari dampak lingkungan, sosial, dan budaya tetapi dampak ekonomi merupakan dampak yang paling ditunggu-tunggu. Hal tersebut demikian karena hampir semua negara atau daerah cenderung mengukur posisi dan manfaat pariwisata dalam hal ekonomi.

Melihat besarnya kontribusi yang ditawarkan oleh industri pariwisata telah mendorong berbagai daerah untuk ikut terlibat dalam mengembangkan industri pariwisata di daerahnya termasuk Bali.
Pembangunan kepariwisataan di Bali merupakan prioritas yang utama disamping pertanian dan industri kecil, dan menjadi andalan bagi pembangunan ekonomi daerah (Budiarti, 2005). Sebagai daerah yang tidak memiliki sumber daya alam yang dapat menghasilkan devisa seperti hutan dan tambang, pembangunan pariwisata yang bermodalkan kebudayaan daerah semakin ditingkatkan sehingga diharapkan mampu memberikan kontribusi dalam hal penerimaan devisa, meningkatkan pendapatan daerah dan kesejahteraan masyarakat, menciptakan lapangan kerja, mendorong kegiatan ekonomi rakyat, pelestarian budaya dan keindahan alam. Bali sebagai ikon daerah tujuan wisata nasional memilki peranan yang sangat penting dalam pencapaian tujuan yang telah ditetapkan pemerintah. Kebijakan otonomi daerahpun diberikan kepada masing-masing kabupaten untuk lebih fokus menggali potensi-potensi pariwisata yang dimiliki.

Pembangunan

kepariwisataan di

Kabupaten Gianyar sebagai salah satu kabupaten di Bali merupakan bagian pembangunan yang diprogramkan oleh 
Pemerintah Kabupaten Gianyar yang berjalan seiring dengan pembangunan pertanian, sektor perindustrian dan sektor ekonomi kreatif. Adapun semua tujuan pembangunan tersebut adalah untuk meningkatkan kesejahteraan serta mampu menaikan taraf perekonomian masyarakat. Kabupaten Gianyar sebagai daerah tujuan wisata di Bali, memiliki beranekaragam potensi wisata khususnya dalam potensi budaya yang sangat menarik untuk dikunjungi.

Pura Gunung Kawi merupakan salah satu daya tarik wisata budaya yang ada di Kabupaten Gianyar. Daya tarik wisata budaya yang dimiliki Pura Gunung Kawi yaitu berupa peninggalan-peninggalan situs purbakala buatan manusia di jaman lampau yang lebih kita kenal dengan isitilah peninggalan arkeologi. Selain memiliki nilai sejarah yang tinggi, Pura ini juga memiliki panorama alam pedesaan yang masih asri, sehingga menjadikan pura ini cukup ramai dikunjungi wisatawan. Hal ini memberikan kesempatan bagi pemerintah dan masyarakat lokal untuk ikut terlibat dalam rangka menunjang kegiatan kepariwisataan melalui penyediaan berbagai fasilitas pariwisata di Pura Gunung Kawi. Salah satu penyediaan fasilitas pariwisata yang paling menonjol terlihat adalah kios-kios pedagang souvenir. Berdasarkan hal tersebut sangat menarik untuk melakukan penelitian untuk menganalisis dampak sosial ekonomi pariwisata terhadap pedagang souvenir di Pura Gunung Kawi Tampaksiring.

\section{TINJAUAN PUSTAKA}

Penelitian ini menggunakan beberapa pedoman konsep dan teori untuk menganalisis data yang diperoleh, yaitu :

1. Konsep daya tarik wisata yang terdiri dari empat komponen, yaitu: Atraksi (Attraction), Aksesibitas (access), Amenitas atau fasilitas (amenities), Ancillary services (Cooper et.al., 1993).

2. Dampak Sosial Ekonomi Pariwisata Dampak pariwisata terhadap kondisi ekonomi masyarakat lokal dapat dikategorikan menjadi delapan kelompok besar (Cohen, 1984). Dalam penelitian ini, peneliti hanya mengidentifikasi 3 dampak berdasarkan keadaan di lapangan yaitu:

1. Dampak pariwisata terhadap kesempatan kerja
2. Dampak pariwisata terhadap pendapatan masyarakat.

3. Dampak pariwisata terhadap harga-harga.

\section{METODE}

Penelitian ini dilakukan di Pura Gunung Kawi Tampaksiring yang terletak di Banjar Penaka, Kecamatan Tampaksiring, Kabupaten Gianyar Provinsi Bali. Adapun jenis data yang digunakan dalam penelitian ini adalah data kualitatif dan data kuantitatif.Data kualitatif dalam penelitian ini yaitu informasi atau keterangan-keterangan yang didapatkan dari informan guna melengkapi penelitian ini seperti sejarah berkembangnya indutri pariwisata, dampak-dampak sosial ekonomi yang dirasakan pedagang souvenir dari adanya kegiatan kepariwisataan di Pura Gunung Kawi Tampaksiring. Sedangkan data kuantitatif dalam penelitian ini seperti daftar nama pemilik kios-kios pedagang souvenir, jumlah penduduk, dan jumlah kunjungan wisatawan ke daya tarik wisata Pura Gunung Kawi Tampaksiring. Penelitian ini menggunakan dua jenis sumber data yaitu : Data Primer adalah data yang diperoleh atau dikumpulkan oleh seorang peneliti atau suatu lembaga tertentu langsung dari sumbernya, dicatat dan diamati untuk pertama kalinya dan hasilnya digunakan langsung oleh peneliti atau oleh lembaga itu sendiri untuk memecahkan permasalahan yang akan dicari jawabannya (Gorda, 1997). Data Sekunder, merupakan sumber yang tidak langsung memberikan data kepada pengumpul data (Sugiyono,2014) Teknik pengumpulan data yang digunakan dalam penelitian ini adalah : observasi, wawancara, penyebaran kuesioner dan studi kepustakaan. Teknik Penentuan Informan yang digunakan adalah purposive sampling (Sugiyono,2010). Adapun dalam menentukan ukuran responden tidak ada aturan yang tegas tentang ukuran reponden yang dipersyaratkan untuk suatu penelitian dari populasi yang tersedia (Nasution, 2011). Jumlah sample yang digunakan dalam penelitian ini adalah sebanyak 41 responden.

\section{HASIL DAN PEMBAHASAN}

Berdasarkan hasil penelitian yang telah dilakukan mengenai dampak dari adanya kegiatan pariwisata di daya tarik wisata Pura Gunung Kawi Tampaksiring terhadap sosial 
ekonomi pedagang souvenir dapat dikemukakan bahwa dampak sosial ekonomi yang terjadi ada 3, yaitu dampak terhadap kesempatan kerja, dampak terhadap pendapatan dan dampak terhadap harga jual produk.

Meninjau dari adanya pedagang souvenir sebagai penunjang kegiatan kepariwisataan di Pura Gunung Kawi Tampaksring, masyarakat yang terlibat sebagai pedagang souvenir adalah sebanyak 41 orang. Sebanyak 34 orang $(82,9 \%)$ diantaranya adalah perempuan dan sisanya sebanyak 7 orang $(17,1 \%)$, adalah laki-laki seperti yang terlihat pada Tabel 4.1

Tabel 4.1

Distribusi Responden Menurut Jenis Kelamin

\begin{tabular}{|c|c|c|c|}
\hline No & Jenis kelamin & $\begin{array}{c}\text { Jumlah } \\
\text { (orang) }\end{array}$ & Persentase (\%) \\
\hline 1 & Laki-laki & 7 & 17,1 \\
\hline 2 & Perempuan & 34 & 82,9 \\
\hline \multicolumn{2}{|c|}{ Jumlah } & 41 & 100 \\
\hline
\end{tabular}

Sumber: Hasil Penelitian Lapangan 2016

Berdasarkan Tabel 4.1 dapat dilihat bahwa sebagian besar masyarakat yang bekerja sebagai pedagang souvenir adalah para kaum perempuan. Hal ini terjadi karena para kaum perempuan juga ingin membantu pendapatan keluarga mereka. Hampir semua dari mereka merupakan penduduk asli Banjar Penaka yaitu sebanyak 40 orang $(97,6 \%)$ berasal dari Banjar Penaka dan sisanya sebanyak 1 orang $(2,4 \%)$ berasal dari Banjar Manukaya, yang dapat dilihat pada Tabel 4.2.

Tabel 4.2

Alamat Responden

\begin{tabular}{|c|l|c|c|}
\hline No & \multicolumn{1}{|c|}{$\begin{array}{c}\text { Alamat } \\
\text { Responden }\end{array}$} & $\begin{array}{c}\text { Jumlah } \\
\text { (orang) }\end{array}$ & Persentase (\%) \\
\hline 1 & $\begin{array}{l}\text { Banjar } \\
\text { Manukaya }\end{array}$ & 1 & 2,4 \\
\hline 2 & Banjar Penaka & 40 & 97,6 \\
\hline & Total & 41 & 100,0 \\
\hline
\end{tabular}

Sumber: Hasil Penelitian 2016

Berdasarkan Tabel 4.2, dapat dikemukakan bahwa dengan adanya kegiatan pariwisata di Pura Gunung Kawi Tampaksiring dapat meningkatkan kesejahteraan hidup masyarakat. Sektor pariwisata telah mampu memberikan wadah kepada masyarakat khususnya kaum perempuan untuk membuka usaha dan dapat mengelolanya secara pribadi seperti terlihat pada tabel 4.3 berikut.

$$
\text { Tabel } 4.3
$$

Status Kepemilikan Usaha Responden

\begin{tabular}{|c|c|c|c|}
\hline No & Status & Jumlah (orang) & Persentase (\%) \\
\hline 1 & Pemilik Usaha & 38 & 92,7 \\
\hline
\end{tabular}

\begin{tabular}{|c|c|c|c|}
\hline 2 & Pengelola & 2 & 4,9 \\
\hline 3 & Karyawan & 1 & 2,4 \\
\hline \multicolumn{2}{|c|}{ Total } & 41 & 100,0 \\
\hline
\end{tabular}

Sumber: Hasil Penelitian 2016

Berdasarkan Tabel 4.3, dapat dilihat bahwa sebanyak 38 orang $(92,7 \%)$ merupakan pemilik usaha, sebanyak 2 orang (4,9\%) adalah pengelola sedangkan sebanyak 1 orang $(2,4 \%)$ merupakan karyawan. Jadi dapat dikatakan bahwa masyarakat cenderung memilih untuk mengelola usahanya sendiri.

\section{Dampak Terhadap Kesempatan Kerja}

Seiring dengan berkembangnya sektor pariwisata di Pura Gunung Kawi Tampaksiring telah memberikan dampak kepada masyarakat terkait dengan memperluas mata pencaharian. Sebagian besar masyarakat Banjar Penaka khususnya kaum wanita juga bekerja sebagai pedagang-pedagang souvenir. Berdasarkan data yang diperoleh dilapangan, hal ini tentunya mendapat respon positif dari para pedagang souvenir yang dapat dilihat pada Tabel 4.4

Tabel 4.4

Pendapat Responden Mengenai Adanya Kesempatan Kerja

\begin{tabular}{|c|l|c|c|}
\hline No & $\begin{array}{c}\text { Pendapat } \\
\text { responden }\end{array}$ & $\begin{array}{c}\text { Jumlah } \\
\text { (orang) }\end{array}$ & $\begin{array}{c}\text { Persentase } \\
(\%)\end{array}$ \\
\hline 1 & Sangat baik & 7 & 17,1 \\
\hline 2 & Baik & 30 & 73,2 \\
\hline 3 & Cukup baik & 4 & 9,8 \\
\hline 4 & Kurang baik & 0 & 0 \\
\hline 5 & Sangat tidak baik & 0 & 0 \\
\hline \multicolumn{2}{|c|}{ Jumlah } & 41 & 100,0 \\
\hline
\end{tabular}

Sumber: Hasil Penelitian 2016

Sebagaimana yang ditunjukkan pada Tabel 4.4, sebanyak 73,2\% pedagang souvenir memberi pendapat baik, $17,1 \%$ memberi pendapat sangat baik, dan sebanyak 9,8\% memberi pendapat cukup baik. Berdasarkan data tersebut dapat disimpulkan bahwa dengan adanya kegiatan pariwisata di Pura Gunung Kawi Tampaksiring ternyata membawa dampak yang baik terhadap kesempatan kerja bagi para pedagang souvenir. Hal ini juga didukung oleh pernyataan dari Ibu Ni Nyoman Rani (32 tahun) yang menyatakan sebagai berikut.

"Perkembangan pariwisata di daerah kami secara perlahan telah mampu memperbaiki perekonomian masyarakat. Setidaknya dengan adanya pariwisata disini, saya dapat membuka usaha kecil-kecilan dengan berdagang souvenir dan bisa membantu suami menambah penghasilan keluarga untuk dapat mecukupi kebutuhan seharihari" (hasil wawancara tanggal 24 Mei 2016). 
Ibu Ni Nyoman Rani merupakan salah satu pedagang souvenir yang ada di daya tarik wisata Pura Gunung Kawi Tampaksiring. Berdasarkan pernyataan tersebut, dapat dikatakan bahwa para pedagang souvenir dapat menyadari dan merasakan dampak dari adanya kegiatan pariwisata terhadap kesempatan kerja. Sektor pariwisata telah memberikan peluang bagi masyarakat untuk membuka usaha melalui berdagang souvenir.

Selain sebagai pedagang souvenir, mereka juga memiliki pekerjaan lainnya untuk menambah penghasilan mereka, baik pekerjaan tersebut dijadikan sebagai pekerjaan utama maupun sampingan. Berdasarkan data yang diperoleh dilapangan, jenis pekerjaan utama dan sampingan pedagang souvenir di daya tarik wisata Pura Gunung Kawi Tampaksiring dapat dilihat pada Tabel 4.6 dan Tabel 4.7.

$$
\text { Tabel 4.6 }
$$

Jenis Pekerjaan Utama Pedagang Souvenir

\begin{tabular}{|c|l|c|c|}
\hline No & \multicolumn{1}{|c|}{ Jenis Pekerjaan } & $\begin{array}{c}\text { Jumlah } \\
\text { (orang) }\end{array}$ & Persentase (\%) \\
\hline 1 & Petani & 3 & 7,3 \\
\hline 2 & Swasta & 2 & 4,9 \\
\hline 3 & $\begin{array}{l}\text { Pengusaha (pedagang } \\
\text { souvenir) }\end{array}$ & 35 & 85,3 \\
\hline 4 & PNS & 0 & 0 \\
\hline 5 & Peternak & 0 & 0 \\
\hline 6 & Buruh & 1 & 2,4 \\
\hline 7 & Dll Jumlah & 0 & 0 \\
\hline \multicolumn{2}{|c|}{ Jum } & 41 & 100 \\
\hline
\end{tabular}

Sumber: Hasil Penelitian Lapangan III 2016

Tabel 4.6 menunjukan bahwa sebanyak $85,3 \%$ pedagang souvenir menjadikan kegiatan membuka usaha atau menjadi pedagang souvenir sebagai jenis pekerjaan utama mereka, sedangkan sebanyak 7,3\% menjadikan profesi petani sebagai pekerjaan utama, $4,9 \%$ sebagai swasta dan sebanyak $2,4 \%$ pekerjaan utamanya sebagai buruh. Sehingga dapat dikatakan bahwa sebagian besar pedagang souvenir sangat bertumpu pada sektor pariwisata di daya tarik wisata Pura Gunung Kawi Tampaksiring.

Sementara itu pada Tabel 4.7 menunjukan bahwa sebanyak 9,8\% menjadikan petani sebagai pekerjaan sampingan, swasta $2,4 \%$, pengusaha $4,9 \%$, buruh $2 \%$, dan merajut sebanyak 46,3\%. Para pedagang souvenir biasanya megisi waktu senggangnya dengan melakukan kegiatan merajut agar mendapatkan pendapatan tambahan sembari menunggu kedatangan wisatawan untuk datang menghampirinya.

Tabel 4.7

Jenis Pekerjaan Sampingan Pedagang Souvenir \begin{tabular}{|l|l|l|l} 
No & Jenis Pekerjaan & Jumlah (orang) & Persentase (\%)
\end{tabular}

\begin{tabular}{|c|l|c|c|}
\hline 1 & Petani & 4 & 9,8 \\
\hline 2 & Swasta & 1 & 2,4 \\
\hline 3 & Pengusaha & 2 & 4,9 \\
\hline 4 & PNS & 0 & 0 \\
\hline 5 & Peternak & 0 & 0 \\
\hline 6 & Buruh & 2 & 4,8 \\
\hline 7 & Merajut & 19 & 46,3 \\
\hline 8 & Tidak menjawab & 13 & 31,8 \\
\hline \multicolumn{2}{|c|}{ Jumlah } & 28 & 100,0 \\
\hline
\end{tabular}

Sumber: Hasil Penelitian Lapangan III 2016

Dampak terhadap kesempatan kerja bagi para pedagang souvenir ternyata sudah lama dapat dirasakan oleh mereka, hal ini dibuktikan dengan diperolehnya data mengenai lama berjualan para pedagang souvenir di Pura Gunung Kawi Tampaksiring. Sebesar 90,2\% berjualan $>5$ tahun, sedangkan para pedagang yang berjualan 3-5 tahun berjumlah sebesar $4,9 \%$, sedangkan $4,9 \%$ lagi berjualan selama 1 3 tahun, seperti yang terlihat pada Tabel 4.8.

\section{Tabel 4.8}

Lama Berjualan Para Pedagang Souvenir Di Pura Gunung Kawi Tampaksiring

\begin{tabular}{|c|c|c|c|}
\hline No & $\begin{array}{c}\text { Kama } \\
\text { berjualan/membuka } \\
\text { usaha }\end{array}$ & $\begin{array}{c}\text { Jumlah } \\
\text { (orang) }\end{array}$ & $\begin{array}{c}\text { Persentase } \\
(\%)\end{array}$ \\
\hline 1 & $<1$ tahun & 0 & 0 \\
\hline 2 & $1-3$ tahun & 2 & 4,9 \\
\hline 3 & $3-5$ Tahun & 2 & 4,9 \\
\hline 4 & $>5$ tahun & 37 & 90,2 \\
\hline \multicolumn{2}{|c|}{ Jumlah } & 41 & 100 \\
\hline
\end{tabular}

Sumber: Hasil Penelitian Lapangan III 2016

Berdasarkan data pada Tabel 4.8 dapat dikatakan bahwa sejalan dengan berkembangnya sektor pariwisata di Pura Gunung Kawi Tampaksiring, penduduk Banjar Penaka telah terlibat dalam rangka menunjang kegiatan pariwisata melalui penyediaan akomodasi/art shop dalam bentuk kios-kios pedagang souvenir.

Namun seiring dengan lamanya keterlibatan masyarakat dalam penyediaan akomodasi (kios pedagang souvenir), maka para pedagang souvenir semakin bisa memahami akan kebutuhan wisatawan. Dengan demikian, para pedagang berupaya untuk memenuhi kebutuhan tersebut dengan menyediakan berbagai jenis souvenir. Adapun jenis-jenis souvenir yang dijual oleh para pedagang bermacam-macam seperti aneka kerajinan tangan yang berupa pernak pernik accesories khas Bali, kain-kain pantai atau yang sering dikenal dengan sebutan sarung, serta aneka pakaian baik pria maupun wanita yang dapat dilihat pada Tabel 4.9 .

Tabel 4.9

Klasifikasi Jenis Souvenir yang Dijual \begin{tabular}{l|l|l|l} 
Jenis & Jumlah & Persentase & Keterangan
\end{tabular} 


\begin{tabular}{|c|c|c|c|c|}
\hline No & $\begin{array}{c}\text { souvenir } \\
\text { yang } \\
\text { dijual } \\
\end{array}$ & (orang) & (\%) & \\
\hline 1 & Pakaian & 12 & 29,3 & $\begin{array}{l}\text { Pakaian yang } \\
\text { berbahan rajutan } \\
\text { merupakan hasil } \\
\text { produksi } \\
\text { masyarakat } \\
\text { sekitar. Sedangkan } \\
\text { aneka jenis } \\
\text { pakaian yang } \\
\text { berbahan kain, } \\
\text { mereka dapatkan } \\
\text { di pasar-pasar seni } \\
\text { tradisional seperti } \\
\text { misalnya Pasar } \\
\text { Seni Sukawati. }\end{array}$ \\
\hline 2 & $\begin{array}{l}\text { Aneka } \\
\text { kerajinan } \\
\text { tangan }\end{array}$ & 9 & 22,0 & $\begin{array}{l}\text { Kerajinan tangan } \\
\text { yang terbuat dari } \\
\text { tempurung kelapa } \\
\text { dan kepala } \\
\text { banteng atau sapi } \\
\text { merupakan } \\
\text { produksi } \\
\text { masyarakat } \\
\text { sekitar. }\end{array}$ \\
\hline 3 & $\begin{array}{l}\text { Pakaian } \\
\text { dan } \\
\text { aneka } \\
\text { kerajinan } \\
\text { tangan }\end{array}$ & 20 & 48,8 & $\begin{array}{l}\text { Pakaian yang } \\
\text { berbahan rajutan } \\
\text { merupakan hasil } \\
\text { produksi } \\
\text { masyarakat } \\
\text { sekitar. Sedangkan } \\
\text { aneka jenis } \\
\text { pakaian yang } \\
\text { berbahan kain, } \\
\text { mereka dapatkan } \\
\text { di pasar-pasar seni } \\
\text { tradisional seperti } \\
\text { misalnya Pasar } \\
\text { Seni Sukawati. } \\
\text { Kerajinan tangan } \\
\text { yang terbuat dari } \\
\text { tempurung kelapa } \\
\text { dan kepala } \\
\text { banteng atau sapi } \\
\text { merupakan hasil } \\
\text { produksi } \\
\text { masyarakat } \\
\text { sekitar. }\end{array}$ \\
\hline & mlah & 41 & 100,0 & \\
\hline
\end{tabular}

Sumber: Hasil Penelitian Lapangan PL III 2016

Pada Tabel 4.9 dapat dilihat bahwa sebanyak 29,3\% pedagang menjual souvenir yang berupa pakaian, sebanyak $22 \%$ menjual aneka kerajinan tangan dan sebanyak 48,8\% menjual pakaian dan aneka kerajinan tangan. Kerajinan tangan yang dijual oleh para pedagang souvenir sebagian besar diproduksi langsung oleh anggota keluarga mereka sendiri (penduduk Banjar Penaka). Sementara untuk souvenir yang berupa pakaian, mereka membelinya di pasar seni tadisional seperti Pasar Seni Sukawati.

\section{Dampak Terhadap Pendapatan}

Pendapatan merupakan hasil yang diperoleh atas pekerjaan yang dilakukan, baik pekerjaan utama maupun sampingan Pendapatan yang diperoleh oleh para pedagang souvenir di Pura Gunung Kawi Tampaksiring masih tergolong minim, di mana hal ini disebabkan karena adanya banyak persaingan. Terdapat banyak sekali pedagang-pedagang souvenir yang menjual barang yang sama. Keseragaman produk yang dijual serta kurangnya etika pedagang dalam menawarkan barang dagangannya sehingga menyebabkan terganggungnya kenyamanan wisatawan. Hal tersebut menjadi salah satu faktor penyebab pendapatan yang mereka peroleh sangat minim. Data mengenai pendapatan dan pengeluaran rata-rata pedagang souvenir dapat dilihat pada Tabel 4.10 dan 4.11.

Tabel 4.10

Penghasilan Rata-Rata Pedagang Souvenir Per Bulan (dalam rupiah)

\begin{tabular}{|c|l|c|c|}
\hline No & \multicolumn{1}{|c|}{$\begin{array}{c}\text { Pendapatan per } \\
\text { bulan }\end{array}$} & Jumlah (orang) & Persentase (\%) \\
\hline 1 & $<$ Rp. 500.000 & 11 & 26,8 \\
\hline 2 & $\begin{array}{l}\text { Rp.500.000- } \\
\text { Rp. } 1.500 .000\end{array}$ & 22 & 53,7 \\
\hline 3 & $\begin{array}{l}\text { Rp.1.501.000- } \\
\text { Rp.2.000.000 }\end{array}$ & 5 & 12,2 \\
\hline 4 & $\begin{array}{l}\text { Rp.2.001.000 - } \\
\text { Rp.2.500.000 }\end{array}$ & 2 & 4,9 \\
\hline 5 & $\begin{array}{l}\text { Rp.2.501.00- } \\
\text { Rp.3.000.000 }\end{array}$ & 1 & 2,4 \\
\hline 6 & $>$ Rp. 3.000 .000 & 0 & 0 \\
\hline \multicolumn{2}{|l}{ Jumlah } & 41 & 100,00 \\
\hline
\end{tabular}

Sumber: Hasil Penelitian Lapangan III 2016

Pada Tabel 4.10 dapat dilihat bahwa dari 41 responden, sebanyak 22 orang memiliki pendapatan rata-rata diantara Rp. 500.000Rp.1.500.000 per bulannya, 11 responden memiliki pendapatan dibawah Rp.500.000 perbulannya, 5 responden memiliki pendapatan rata-rata diantara Rp.1.501.000-Rp.2.000.000, 2 orang responden memilki pendapatan ratarata diantara Rp.2.001.000-Rp.2.500.000, dan 1 respon yang memiliki pendapatan diantara Rp.2.501.00- Rp.3.000.000. Pada tabel 4.5 dapat dilihat bahwa dari 41 responden, sebanyak 22 orang memiliki pendapatan ratarata diantara Rp.500.000- Rp.1.500.000 per bulannya, 11 responden memiliki pendapatan dibawah Rp.500.000 perbulannya, 5 responden memiliki pendapatan rata-rata diantara Rp.1.501.000- Rp.2.000.000, 2 orang responden memilki pendapatan rata-rata diantara Rp.2.001.000- Rp.2.500.000, dan 1 responden yang memiliki pendapatan diantara Rp.2.501.00-Rp. 3.000.000. 
Sementara itu Tabel 4.11 menunjukan bahwa sebanyak 16 responden memiliki pengeluaran rata-rata diantara Rp.1.501.000Rp.2.000.000, 14 responden memiliki pengeluaran rata-rata diantara Rp. 500.000Rp. $1.500 .000,6$ responden memiliki pengeluaran rata-rata dibawah $500.000,3$ orang responden memiliki pengeluaran ratarata diantara Rp.2.001.000- Rp.2.500.000, sedangkan sebanyak 2 responden memiliki pengeluaran rata-rata diantara Rp.2.501.000 Rp.3.000.000.

Tabel 4.11

Pengeluaran Rata-Rata Pedagang Souvenir Per Bulan (dalam rupiah)

\begin{tabular}{|l|l|c|c|}
\hline No & $\begin{array}{l}\text { Pengeluaran per } \\
\text { bulan }\end{array}$ & $\begin{array}{l}\text { Jumlah } \\
\text { (orang) }\end{array}$ & Persentase (\%) \\
\hline 1 & $<$ Rp.500.000 & 6 & 14,6 \\
\hline 2 & $\begin{array}{l}\text { Rp. } 500.000- \\
\text { Rp.1.500.000 }\end{array}$ & 14 & 34,1 \\
\hline 3 & $\begin{array}{l}\text { Rp.1.501.000- } \\
\text { Rp.2.000.000 }\end{array}$ & 16 & 39,0 \\
\hline 4 & $\begin{array}{l}\text { Rp.2.001.000- } \\
\text { Rp.2.500.000 }\end{array}$ & 3 & 7,3 \\
\hline 5 & $\begin{array}{l}\text { Rp.2.501.000- } \\
\text { RP.3.000.000 }\end{array}$ & 2 & 4,9 \\
\hline 6 & $>$ Rp.3.000.000 & 0 & 0 \\
\hline \multicolumn{2}{|c|}{ Jumlah } & 41 & 100 \\
\hline
\end{tabular}

Sumber: Hasil Penelitian Lapangan III 2016

Tabel 4.12

Pengeluaran rata-rata per kapita Sebulan (dalam rupiah) Provinsi Bali Tahun 2015

\begin{tabular}{|c|c|c|c|}
\hline No & Jenis Pengeluaran & Jumlah (rupiah) & Persentase (\%) \\
\hline 1 & \begin{tabular}{lr}
\multicolumn{2}{l}{ Pengeluaran } \\
rata rata- \\
sebulan & perkapita \\
kelompok & bahurut \\
makanan & Provinsi \\
Bali. &
\end{tabular} & Rp. 421.577 & 40,3 \\
\hline 2 & \begin{tabular}{lr}
\multicolumn{2}{l}{ Pengeluaran rata- } \\
rata & perkapita \\
sebulan & menurut \\
kelompok & bukan \\
bahan & makanan \\
Provinsi Bali.
\end{tabular} & Rp. 623.568 & 59,7 \\
\hline & Jumlah total & Rp. 1.045.145 & 100 \\
\hline
\end{tabular}

Sumber : Diolah dari data BPS Provinsi Bali

Berdasarkan data Tabel 4.11 dapat dikatakan bahwa pengeluaran rata-rata pedagang souvenir lebih besar dari pendapatan rata-rata yang diperoleh setiap bulannya. Oleh karena sebagian besar pedagang souvenir adalah kaum wanita, jadi mereka bekerja untuk membantu memenuhi kebutuhan keluarganya bukan sebagai tulang punggung keluarga. Ditinjau dari pengeluaran rata-rata pedagang souvenir di Pura Gunung Kawi Tampaksiring dapat dikatakan cukup besar jika dibandingankan dengan data pengeluaran rata-rata per kapita
Sebulan (dalam rupiah) Provinsi Bali Tahun 2015 yang dapat dilihat pada Tabel 4.12

\section{Dampak Terhadap Harga Jual Produk}

Perkembangan sektor pariwisata di Pura Gunung Kawi Tampaksiring juga memberikan dampak terhadap harga jual produk yang dijual oleh para pedagang souvenir. Berdasarkan data yang telah diperoleh di lapangan, sebanyak 32 responden (78\%) mengatakan bahwa harga jual produk saat ini di Pura Gunung Kawi adalah semakin murah, sebanyak 5 responden yang mengatakan harga jual produk saat ini tetap/tidak berpengaruh dan sebanyak 4 responden yang mengatakan semakin mahal, seperti yang terlihat pada Tabel 4.13 .

Tabel 4.13

Pendapat Responden Mengenai Pengaruh Pariwisata Terhadap Harga Jual Produk

\begin{tabular}{|c|l|c|c|}
\hline No & \multicolumn{1}{|c|}{ Harga jual produk } & $\begin{array}{c}\text { Jumlah } \\
\text { (orang) }\end{array}$ & Persentase (\%) \\
\hline 1 & Semakin mahal & 4 & 9,8 \\
\hline 2 & $\begin{array}{l}\text { Tetap/tidak } \\
\text { berpengaruh }\end{array}$ & 5 & 12,2 \\
\hline 3 & Semakin murah & 32 & 78,0 \\
\hline \multicolumn{2}{|c|}{ Jumlah } & 41 & 100,0 \\
\hline
\end{tabular}

Sumber: Hasil Penelitian Lapangan III 2016

Berdasarkan data Tabel 4.13 dapat dikatakan bahwa perkembangan sektor pariwisata di Pura Gunung Kawi saat ini memberi dampak yang negatif terhadap harga jual produk. Setelah ditelusuri lebih jauh, ternyata kesimpulan bahwa turunnya harga produk disebabkan oleh pariwisata, maksudnya adalah menurunnya harga jual produk disebabkan oleh persaingan yang tidak sehat dengan menetapkan harga jual produk serendah-rendahnya. Hal ini, misalnya, diperkuat oleh pernyataan salah seorang informan, I Wayan Sedeng yang menyatakan pernyataan sebagai berikut.

"Harga jual produk-produk souvenir saat ini sangat anjlok. Untung yang didapat dari produk yang dijual sangat tipis, tidak seperti dulu. Hal ini sudah terjadi pasca bom Bali. Memang benar ada banyak wisatawan yang mengunjungi Pura Gunung Kawi, tapi hanya sebagian kecil dari mereka yang mau belanja. Sehingga mulailah terjadi perang harga antar pedagang saat ini" (hasil wawancara tanggal 24 Mei 2016).

\section{SIMPULAN DAN SARAN}

Perkembangan sektor pariwisata di Pura Gunung Kawi Tampaksiring membawa dampak sosial ekonomi yang cukup besar terhadap pedagang-pedagang souvenir, yaitu diantaranya: 
1. Dampak terhadap kesempatan kerja Perkembangan sektor pariwisata di daya tarik wisata Pura Gunung Kawi Tampaksiring ternyata membawa dampak positif terhadap kesempatan kerja yaitu dapat memperluas lapangan pekerjaan untuk masyarakat sekitar. Hal ini tentu mendapat respon positif dari masyarakat khususnya bagi para pedagang souvenir. Pariwisata telah memberikan peluang bagi mereka untuk membuka usaha, yaitu dengan berdagang aneka souvenir sehingga bisa mengurangi angka pengangguran.

2. Dampak terhadap pendapatan

Pendapatan yang diperoleh pedagang souvenir masih tergolong minim.Dalam 1 bulan sebagian besar dari mereka hanya memperoleh penghasilan ratarata sebesar Rp.500.000-Rp.1.500.000. Hal ini disebabkan karena banyaknya persaingan dengan keseragaman produk yang dijual serta kurangnya etika pedagang dalam berjualan yang terkesan memaksa wisatawan untuk membeli produk mereka.

3. Dampak terhadap harga jual produk Menurunnya harga jual produk disebabkan oleh persaingan yang tidak sehat dengan menetapkan harga jual produk serendah-rendahnya. Saat ini harga jual produk semakin murah, sehingga untung yang diperoleh pedagang souvenir sangat tipis.

Adapun saran yang dapat diberikan yaitu :

1. Memperbaiki tata kelola keberadaan dari kios-kios pedagang souvenir. Pengelola daya tarik wisata Pura Gunung kawi harus berupaya untuk lebih menertibkan lagi kios-kios pedagang tersebut agar terlihat lebih rapi dan teratur sehingga enak untuk dipandang.

2. Memberi pelatihan kepada para pedagang terkait dengan penggunaan bahasa yang baik dan benar serta etika untuk berdagang agar bisa memberikan pelayanan yang lebih baik lagi kepada wisatawan sehingga tidak mengganggu kenyamanan wisatawan.
3. Memberikan motivasi kepada para pengrajin untuk terus berinovasi dalam menciptakan suatu karya kerajinan tangan yang baru dan unik sehingga variasi produk semakin banyak.

\section{DAFTAR PUSTAKA}

Budiarti. 2005. Pengelolaan Pengembangan Ekowisata di Kawasan Hutan Mangrove Benoa Bali. Tesis. Udayana University

Cohen, Erik. 1984. The Sociology of Tourism : Approaches, Issues and Findings. Annual Review of Sociology. Vol.10. Jerusalem: Department of Sociology Hebrew University of Jerusalem

Cooper, Chris., et al. 1993. Tourism Principles \& Practice. United Kingdom: Longman Group Limited.

Gorda, I Gst Ngurah. 1997. Metodologi Penelitian Ilmu Sosial Ekonomi. Denpasar: PT. Widya Kriya Gematama

Nasution, 2011. Metode Research Penelitian Ilmiah. Jakarta: PT Bumi Aksara.

Sugiyono. 2010. Metode Penelitian Pendidikan (Pendekatan Kuantitatif, Kualitatif dan R\&D). Bandung: Alfabeta

Sugiyono. 2014. Metode Penelitian Kuantitatif, Kualitatif, dan Kombinasi (Mixed Methods). Bandung: Alfabeta

Suwantoro, Gamal. 2001. Dasar-dasar Pariwisata. Yogyakarta: Penerbit Andi

Wahab, S. 2007. Manajemen Kepariwisataan. Jakarta Pradnya Paramitha. 